\title{
Performance Testing of New Chrysanthemum (Dendranthema grandiflora Tzvelev) Genotypes for Loose Flower and Pot Culture Production
}

\author{
P. Prasanth ${ }^{*}$, Z. Salma and S. Praneeth Kumar
}

Floricultural Research Station, SKLTSHU, ARI, Rajendranagar, Hyderabad - 500 030, India

*Corresponding author

\section{A B S T R A C T}

\begin{tabular}{l}
\hline Ke y w o r d s \\
$\begin{array}{l}\text { Chrysanthemum, } \\
\text { Genotypes, Loose } \\
\text { flower, Pot culture }\end{array}$ \\
\hline Article Info \\
\hline $\begin{array}{l}\text { Accepted: } \\
\text { 26 July 2020 } \\
\text { Available Online: } \\
\text { 10 August } 2020\end{array}$ \\
\hline
\end{tabular}

An experiment was conducted to evaluate the performance of fifteen (15) new chrysanthemum genotypes for loose flower (7) and pot culture (8) for three years (2015-16 to 2017-18) at Floricultural Research Station, SKLTSHU, Hyderabad. The results revealed that, among loose flower genotypes maximum plant height $(46.75 \mathrm{~cm})$ was recorded in Bidhan Madhuri and minimum $(26.20 \mathrm{~cm}$ ) in Arka Yellow Gold. Earliest in flower bud appearance (60.44 days) was noticed in HCC-2 followed by Bidhan Purna (61.55). Maximum number of flowers per plant (68.60) was observed in HCC-2 and minimum in Arka Yellow Gold (30.61). Among pot culture genotypes, maximum plant height (50.12 $\mathrm{cm})$ was recorded in Pusa chitraksha and minimum $(17.86 \mathrm{~cm}$ ) in Arka Pink Star. Highest number of branches per plant (17.87) was registered in Arka Kirti and minimum (6.31) in Arka Usha Kiran. Further, maximum number of flowers per plant (226.40) was recorded in Bidhan Tarun and minimum in Pusa Adithya (97.76). From the results it can be concluded that, Bidhan Purna, Bidhan Maduri, HCC-2 are suitable for loose flower and Bidhan Tarun, HCC-2, Pusa Chitraksha, Arka Pink Star for pot culture production.

\section{Introduction}

Chrysanthemum a Astreraceae member commonly called as Queen of the East, and has become popular as commercial flower crop in all parts of the world.

It is a short day plant and has two phases in its growth cycle, long days (> 12 hours) are required for vegetative growth and short days ( $<12$ hours) for induction and development of flowering. Thus, photoperiodic responses influence the growth and development in chrysanthemum genotypes.
The wide variation in flower colours, sizes, petal shapes and structures make it more valuable flower crop for different purposes viz. loose flower, cut flower, pot mums, garden plant etc. It is cultivated over a wide range of climatic conditions, but growth of a definite cultivar varies with environmental factors like temperature and photoperiod. The successful cultivation of chrysanthemum depends on the interaction of the cultivar with specific environment where it is growing. Every year many numbers of cultivars are introduced in chrysanthemum depending on the preferences of the farmers and consumers. 
Hence, identifying the suitable cultivars for a particular region for determined purpose is very imperative in chrysanthemum. Evaluation of new genotypes for distinct environment is always necessary to study the quality traits under varying climatic conditions. In view of the above facts, present research was conducted to assess the performance of new genotypes of chrysanthemum for loose flower and pot culture under Hyderabad conditions.

\section{Materials and Methods}

The experiment was conducted at Floriculture Research Station, SKLTSHU for three years during 2015-16 to 2017-18. The experimental site comes under semi arid tropical climate with an average rainfall of $615.6 \mathrm{~mm}$, located at an altitude of 542.3 above mean sea level at latitude of $17.90^{\circ}$ North and longitude of $78.23^{0}$ East. Seven genotypes of loose flower and eight genotypes of pot plants were evaluated in the investigation.

The loose flower experiment was carried out in Randomized Block Design with three replications with spacing of $30 X 40 \mathrm{~cm}$ and 30 plants were planted in each replication. Pot culture experiment was conducted in Completely Randomized Design with three replications. Nine inch size pots were used with standard media, each pot was planted with single plant. Uniform cultural operations were subjected to all the genotypes throughout the experimental period.

Five randomly tagged plants per replication were used for recording various observations on vegetative parameters viz. plant height $(\mathrm{cm})$, plant spread $(\mathrm{cm})$, number of branches per plant; floral parameters viz. day to first bud appearance, days to 50 per cent flowering, flower diameter; yield parameters viz. number of flowers per plant. The data recorded was statistically analysed using
OPSTAT software and the difference of means was compared at five per cent level of significance.

\section{Results and Discussion}

\section{Mean performance of loose flower genotypes for vegetative and floral characters}

The data pertaining to loose flower genotypes recorded significant differences for the traits studied is presented in the Table 1. Among the seven genotypes evaluated, the mean plant height for three years ranged from 46.75 to $26.20 \mathrm{~cm}$. Maximum plant height $(46.75 \mathrm{~cm})$ was recorded in Bidhan Madhuri followed by Bidhan Purna $(41.90 \mathrm{~cm})$ without significant difference.

Whereas, minimum plant height $(26.20 \mathrm{~cm})$ was registered in Arka Yellow Gold. Plant growth is usually a good index of plant vigour, which may contribute towards greater productivity (Jeebit Singh et al., 2019). The variation in plant height might be due to their genetic makeup of the individual genotype (Rajiv Kumar, 2014). Similar variation in plant height among genotypes was also recorded in chrysanthemum by Kim et al., (2014) and Suvija et al., (2016).

Days to first bud appearance ranged from 60.44 to 106.33 days. The earliest flower bud appearance (60.44 days) was noticed in HCC2 genotype and maximum (106.33 days) was registered in Arka Yellow Gold. Remaining genotypes showed intermediate results without significant difference. Days to 50 per cent flowering were recorded maximum (120.07 days) in HCC-3 and minimum (104.96 days) in Bidhan Purna. The variation for late or early flowering seems to be genetically controlled character in genotypes and have been reported by Rao and Pratap (2006) and Roopa et al., (2018). 
Table.1 Mean performance of loose flower genotypes of chrysanthemum for vegetative and floral characters

\begin{tabular}{|l|l|c|c|c|}
\hline S. No. & \multicolumn{1}{|c|}{ Genotype } & $\begin{array}{c}\text { Plant height } \\
\text { (cm) }\end{array}$ & $\begin{array}{c}\text { Days to first bud } \\
\text { appearance (days) }\end{array}$ & $\begin{array}{c}\text { Days to } \\
\text { 50\%flowering }\end{array}$ \\
\hline $\mathbf{1}$ & Arka Yellow Gold & 26.20 & 106.33 & 117.99 \\
\hline $\mathbf{2}$ & Bidhan Jayanthi & 30.19 & 71.22 & 117.93 \\
\hline $\mathbf{3}$ & Bidhan Madhuri & 46.75 & 73.58 & 122.67 \\
\hline $\mathbf{4}$ & Bidhan Purna & 41.90 & 61.55 & 104.96 \\
\hline $\mathbf{5}$ & HCC-1 & 33.36 & 82.07 & 119.56 \\
\hline $\mathbf{6}$ & HCC-2 & 32.19 & 60.44 & 106.13 \\
\hline $\mathbf{7}$ & HCC-3 & 29.39 & 76.78 & 120.07 \\
\hline & SE (m) & 3.18 & 5.61 & 3.52 \\
\hline & CD 5\% & 9.91 & 17.48 & 10.95 \\
\hline
\end{tabular}

Table.2 Mean performance of loose flower genotypes of chrysanthemum for flower quality and yield attributes

\begin{tabular}{|l|l|c|c|}
\hline S. No. & \multicolumn{1}{|c|}{ Genotype } & $\begin{array}{c}\text { Diameter of } \\
\text { flower }(\mathbf{c m})\end{array}$ & $\begin{array}{c}\text { No. of } \\
\text { flowers/plant }\end{array}$ \\
\hline $\mathbf{1}$ & Arka Yellow Gold & 4.84 & 30.61 \\
\hline $\mathbf{2}$ & Bidhan Jayanthi & 4.97 & 41.46 \\
\hline $\mathbf{3}$ & Bidhan Madhuri & 5.41 & 51.24 \\
\hline $\mathbf{4}$ & Bidhan Purna & 5.39 & 58.04 \\
\hline $\mathbf{5}$ & HCC-1 & 2.78 & 64.82 \\
\hline $\mathbf{6}$ & HCC-2 & 3.38 & 68.60 \\
\hline $\mathbf{7}$ & HCC-3 & 6.35 & 35.35 \\
\hline & SE (m) & 0.26 & 5.23 \\
\hline & CD 5\% & 0.81 & 16.29 \\
\hline
\end{tabular}

Table.3 Mean performance of pot culture genotypes of chrysanthemum for vegetative characters

\begin{tabular}{|l|l|c|c|c|}
\hline S. No. & \multicolumn{1}{|c|}{ Genotype } & Plant height (cm) & Plant spread (cm) & $\begin{array}{c}\text { No of } \\
\text { branches/plant }\end{array}$ \\
\hline $\mathbf{1}$ & Arka kirti & 41.38 & 40.12 & 17.87 \\
\hline $\mathbf{2}$ & Arka Pink Star & 17.86 & 43.00 & 10.80 \\
\hline $\mathbf{3}$ & Bidhan Mum & 41.34 & 31.00 & 7.78 \\
\hline $\mathbf{4}$ & Bidhan Tarun & 43.77 & 35.63 & 11.40 \\
\hline $\mathbf{5}$ & HCC-2 (Check) & 43.20 & 41.63 & 14.69 \\
\hline $\mathbf{6}$ & Pusa Adithya & 41.74 & 36.34 & 9.78 \\
\hline $\mathbf{7}$ & Pusa Chitraksha & 50.12 & 45.55 & 12.42 \\
\hline $\mathbf{8}$ & Arka Usha Kiran & 30.08 & 29.90 & 6.31 \\
\hline & SE(m) & 3.01 & 2.40 & 1.11 \\
\hline & CD 5\% & 9.11 & 7.27 & 3.35 \\
\hline
\end{tabular}


Table.4 Mean performance of pot culture genotypes of chrysanthemum for flowering and yield characters

\begin{tabular}{|l|l|c|c|c|}
\hline S. No. & \multicolumn{1}{|c|}{ Genotype } & $\begin{array}{c}\text { Days to first bud } \\
\text { appearance }\end{array}$ & $\begin{array}{c}\text { Diameter of } \\
\text { flower }(\mathbf{c m})\end{array}$ & $\begin{array}{c}\text { No. of } \\
\text { flowers/plant }\end{array}$ \\
\hline $\mathbf{1}$ & Arka kirti & 85.89 & 4.86 & 140.78 \\
\hline $\mathbf{2}$ & Arka Pink Star & 72.00 & 3.19 & 185.22 \\
\hline $\mathbf{3}$ & Bidhan Mum & 78.40 & 3.73 & 78.82 \\
\hline $\mathbf{4}$ & Bidhan Tarun & 81.93 & 4.99 & 226.40 \\
\hline $\mathbf{5}$ & HCC-2 (Check) & 73.82 & 4.21 & 218.31 \\
\hline $\mathbf{6}$ & Pusa Adithya & 70.58 & 4.96 & 97.76 \\
\hline $\mathbf{7}$ & Pusa Chitraksha & 86.56 & 4.47 & 190.13 \\
\hline $\mathbf{8}$ & Arka Usha Kiran & 83.96 & 5.58 & 125.63 \\
\hline & SE(m) & 2.84 & 0.24 & 17.42 \\
\hline & CD 5\% & 8.59 & 0.72 & 52.68 \\
\hline
\end{tabular}

Mean performance of loose flower genotypes for flower quality and yield characters

It is vivid from the table 2, flower quality and yield characters differed significantly among genotypes. The flower diameter was recorded maximum $(6.35 \mathrm{~cm})$ in HCC-3 followed by Bidhan Madhuri $(5.41 \mathrm{~cm})$ and Bidhan Purna $(5.39 \mathrm{~cm})$. Whereas minimum $(2.78 \mathrm{~cm})$ flower diameter was observed in HCC-1. Maximum number of flowers per plant (68.60) was recorded in HCC-2 which was followed by HCC-1 (64.82) and Bidhan Purna (58.04) without any significant difference. However, minimum (30.61) number of flowers per plant was registered in Arka Yellow Gold. This variation in flower number per plant might due to their genetical nature that could be influenced by the environmental conditions viz. temperature and photoperiod prevailed during experimental period as reported by Punetha et al., (2011).

\section{Mean performance of pot culture genotypes for vegetative characters}

The mean data recorded for vegetative and flowering traits of pot chrysanthemums is indicated in the Table 3. The mean plant height of three years among the eight genotypes ranged from 30.08 to $50.12 \mathrm{~cm}$. The maximum plant height $(50.12 \mathrm{~cm})$ was recorded in Pusa Chitraksha which was on par with all genotypes except Arka Usha Kiran (30.08). Maximum plant spread $(45.55 \mathrm{~cm})$ was documented in Pusa Chitraksha which was on par with Arka Pink Star $(43.00 \mathrm{~cm})$, HCC-2 $(41.63 \mathrm{~cm})$ and Arka kirti $(40.12 \mathrm{~cm})$. Whereas, minimum plant spread $(29.90 \mathrm{~cm})$ was noticed in Arka Usha Kiran. Number of branches per plant was registered maximum (17.87) in Arka kirti which was on par with HCC-2 (14.69) and minimum (6.31) was observed in Arka Usha Kiran. The variation in growth parameters among the genotypes may be due to the hereditary character, as all plants were similar cultural practices under same environmental conditions. Similar results were given by Baskaran et al., (2016) and Kumar et al., (2007). Further, increase in plant spread corresponded with increase in number of branches per plant.

Mean performance of pot culture genotypes for flowering and yield characters

The variations in flowering and yield characters are documented in table 4. Early 
flower bud appearance (70.58 days) was observed in Pusa Adithya which was on par with Arka Pink Star (72.00 days), HCC-2 (73.82 days) and Bidhan Mum (78.40 days). However, late bud appearance was noticed in Pusa Chitraksha (86.56 days). Maximum flower diameter $(5.58 \mathrm{~cm})$ was registered in Arka Usha Kiran which was on par with Bidhan Tarun (4.99 cm), Pusa Adithya (4.96 $\mathrm{cm})$ and Arka Kirti $(4.86 \mathrm{~cm})$. Significantly minimum flower diameter $(3.19 \mathrm{~cm})$ among all genotypes was documented in Arka Pink Star.

The maximum number of flowers per plant (226.40) was recorded in Bidhan Tarun which was on par with HCC-2 (218.31), Pusa Chitraksha (190.13) and Arka Pink Star (185.22). Minimum number of flowers per plant (78.82) was noticed in Bidhan Mum. Higher yield might be due to increase in vegetative parameters which might have contributed in production of more photosynthates resulting in production of more number of flowers per plant. The present results are in accordance with the results reported by Reddy et al., (2016); Palai et al., (2018) and Jeebit Singh et al., (2019).

In conclusion the based on the above results, it can be concluded that, among loose flower genotypes Bidhan Purna, Bidhan Maduri, HCC-2 performed well and are suitable for loose flower production in this region. Whereas, for pot culture Bidhan Tarun, HCC2, Arka Pink Star and Pusa Chitraka are found to be best.

\section{References}

Baskaran, V., Jayathi, R., Janakiram, T. and Abirami, K., 2016, Studies on genetic variability, heritability and genetic advance in chrysanthemum. J. of Horticultural Sci., 4(2):174- 176.

Jeebit Singh, L., Khangjarakpam, G.,
Shadkan, R. and Dhua, R.S., 2019, Quality characterization of new chrysanthemum genotypes. $J$. of Pharmacognosy and Phytochem., 8(4): 1611- 1617.

Kim, S. J., Lee, C.H., Kim, J. and Kim, K.S., 2014, Phylogenetic analysis of Korean native chrysanthemum species based on morphological characteristics. Scientia Horticulturae., 175: 278-289.

Kumar, R., Yadav, D.S. and Roy, A. R., 2007, Performance of chrysanthemum (Dendranthema grandiflora Tzvelev) cultivars under sub-tropical mid hills altitude of Meghalaya. Environment and Ecology., 25(3A): 941-945.

Palai, S.K., Madhuri, G., Nath, M. R. and Bhuyan, S., 2018, Effect of planting dates and photoperiod on growth and flowering of chrysanthemum (Chrysanthemum morifolium Ramat.) cv. Yellow Reagan. The Pharma Innova., 17(5): 106-108.

Punetha, P., Rao, V. K. and Sharma, S.K., 2011, Evaluation of different chrysanthemum (Chrysanthemum morifolium) genotypes under mid hill condition of Gharwal Himalaya. The Indian J. Agric. Sci., 81(9)

Rajiv Kumar, 2014, Evaluation of chrysanthemum genotypes for flowering traits under open grown condition. Hort. Flora Res. Spectrum, 3(4): 388-389.

Rao, A. M. and Pratap, M., 2006, Evaluation of varities and variability studies in chrysanthemum (Dendranthema grandiflora Tzvelev.). J. of Orna. Horti., 9(3): 221-223.

Reddy, A. M., Jyothi, U. K., Vani, S.V. and Reddy, A. R., 2016, Evaluation of chrysanthemum (Dendranthema grandiflora Tzvelev) cultivars for flower and postharvest quality in alfisols of coastal Andhra Pradesh. Annals of Hort., 9(1): 4-8.

Roopa, S., Chandrashekar, S.Y., Shivaprasad, 
M., Hanumantharaya, L. and Hemanth Kumar, 2018, Evaluation of chrysanthemum (Dendranthema grandiflora Tzvelev) genotypes for floral and quality traits under hill zone of Karnataka, India. Int. J. Curr. Microbiol. App. Sci., 7(8):1874-1879.

Suvija, N.V., Kannan, M., Suresh, J. and
Subesh, R.K., 2016, Evaluation of chrysanthemum (Chrysanthemum morifolium Ramat) genotypes for loose flower, cut flower and pot mums. Inter. J. Innov. Res. and Adv. Studies, 3(4):100-103.

\section{How to cite this article:}

Prasanth, P., Z. Salma and S. Praneeth Kumar. 2020. Performance Testing of New Chrysanthemum (Dendranthema grandiflora Tzvelev) Genotypes for Loose Flower and Pot Culture Production. Int.J.Curr.Microbiol.App.Sci. 9(08): 3426-3431. doi: https://doi.org/10.20546/ijcmas.2020.908.396 